\title{
Photosynthesis response to severe water deficit in terminal stems of Myriolimon ferulaceum
}

\author{
M.À. CONESA ${ }^{+}$and J. GALMÉS \\ Research Group on Plant Biology under Mediterranean Conditions, Universitat de les Illes Balears-INAGEA, \\ Ctra. Valldemossa km. 7.5, 07122 Palma, Balearic Islands
}

\begin{abstract}
Myriolimon ferulaceum is a leafless species and close relative to Limonium inhabiting the same harsh environments in the rocky coast and salt marshes, with discontinuous distribution in western and central coast of the Mediterranean Basin and southern Iberian Peninsula. In order to test for the drought adaptive importance of photosynthesis in stems, and to decipher advantages and drawbacks of stem $v$ s. leaf photosynthesis under drought conditions, M. ferulaceum was grown under the well-watered and severe water deficit conditions used in previous experiments with Limonium. Growth, stem anatomy, photosynthesis and gas exchange, and Rubisco-related traits were measured. Growth capacity in M. ferulaceum was higher than that of many Limonium under well-watered conditions, where limitations to photosynthesis were mostly biochemical. However, severe water deficit conditions had a higher impact in the leafless species, where the main photosynthesis limitation was stomatal conductance. High intrinsic water-use efficiency under well-watered conditions and high mesophyll conductance to stomatal conductance ratio under severe water deficit conditions were the main drivers of growth capacity in M. ferulaceum.
\end{abstract}

Additional key words: biomass; limitation analysis; rbcL; Rubisco kinetics; water consumption; water stress.

\section{Introduction}

Drought stress, frequently associated with high temperature and radiation, is the most important constraint to plant survival and consequently one of the main drivers of plant adaptation to the environment (Chaves et al. 2003, 2009). Diverse strategies to overcome drought stress have been described across species, environments, and growth forms (e.g. Ludlow 1989, Chaves et al. 2002, Lawlor and Cornic 2002, Munns, 2002, Bréda et al. 2006, McDowell et al. 2008, Nardini et al. 2014). Although the leaf is the main photosynthetic organ in plants, some $\mathrm{C}_{3}$ species from arid and semiarid habitats cope with drought through different degrees of deciduousness (e.g. Nilsen and Sharifi 1997, Galmés et al. 2005, Correia and Ascensão 2017). In such cases, the photosynthesis $\left(P_{\mathrm{N}}\right)$ of green stems has an important role in plant survivorship (Nilsen 1995, Aschan and Pfanz 2003, Ávila et al. 2014).

Two photosynthetic syndromes have been proposed in green stems of nonsucculent plants, namely, stem net $P_{\mathrm{N}}$ and stem recycling $P_{\mathrm{N}}$. The former occurs in stems with high stomata densities. The latter includes the cortical $P_{\mathrm{N}}$ in stems with poor or no stomata, and is also expected to occur in plants with stem net $P_{\mathrm{N}}$ (Ávila et al. 2014). Recycling $P_{\mathrm{N}}$ involves a large proportion of refixation of the respired $\mathrm{CO}_{2}$. Depending on the species, it can be an important part of the overall plant carbon economy, although leaf $P_{\mathrm{N}}$ usually constitutes the main bulk. The stem net $P_{\mathrm{N}}$ is frequent in leafless desert and Mediterranean species in which the stems are the main photosynthetic organs substituting the leaf function (reviewed in Ávila et al. 2014, Vandegehuchte et al. 2015). Moreover, the stem stomatal conductance $\left(g_{\mathrm{s}}\right)$ is proportionally lower than that of the leaf (Osmond et al. 1987, Comstock and Ehleringer

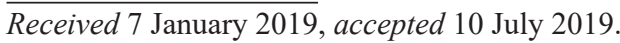

${ }^{+}$Corresponding author; phone: +34971171340, fax: +34971173168, e-mail: ma.conesa@uib.es

Abbreviations: $\mathrm{B}_{\mathrm{T}}$ - total plant biomass; $C_{\mathrm{c}}$ - chloroplastic $\mathrm{CO}_{2}$ concentration; Ep - epidermis area; ETR - electron transport rate; $g_{\mathrm{m}}$ - mesophyll conductance; $g_{\mathrm{s}}$ - stomatal conductance; $g_{\mathrm{tot}}$ - total leaf conductance to $\mathrm{CO}_{2} ; J_{\max }$ - maximum electron transport rate; $K_{\mathrm{c}}, K_{\mathrm{o}}$ - Michaelis-Menten constants for $\mathrm{CO}_{2}$ and for $\mathrm{O}_{2} ; k_{\text {cat }}^{\mathrm{c}}, k_{\text {cat }}^{\mathrm{o}}-$ maximum rate of carboxylation and oxygenation; $l_{\mathrm{b}}-$ biochemical limitation; $l_{\mathrm{m}}$ - mesophyll limitation; $l_{\mathrm{s}}$ - stomatal limitation; $\mathrm{Mes}^{\mathrm{air}}$, Mes ${ }^{\mathrm{cell}}$, Mes ${ }^{\text {total }}-$ area of mesophyll airspaces, cells, and total, respectively; $P_{\mathrm{g}}-\mathrm{CO}_{2}$ assimilation rate per unit leaf area; $P_{\mathrm{N}}-$ net $\mathrm{CO}_{2}$ assimilation rate per unit leaf area; $\mathrm{R} / \mathrm{S}-\mathrm{root} / \mathrm{shoot}$ ratio; $r b c \mathrm{~L}$ - Rubisco large subunit gene; RWC - relative water content; $\mathrm{Scl}$ - sclereids area; $\mathrm{S}_{\mathrm{c} / \mathrm{o}}-$ Rubisco specificity factor for $\mathrm{CO}_{2} / \mathrm{O}_{2}$; Vas - vascular tissue area; $V_{\text {cmax }}$ - maximum velocity of carboxylation; WC - water consumption; WD - severe water deficit treatment; $\mathrm{WUE}_{\mathrm{b}}$ - whole plant water-use efficiency; $\mathrm{WUE}_{\mathrm{i}}$ - intrinsic water-use efficiency; WW - well-watered treatment; $\Phi_{\mathrm{CO} 2}-$ quantum yield of $\mathrm{CO}_{2} ; \Phi_{\mathrm{PSII}}$ - quantum yield of PSII.

Acknowledgements: This research was supported by the project AGL2009-07999 (Plan Nacional, Spain) awarded to JG. The authors thank Arantzazu Molins and Marcel Font for Rubisco kinetics and specificity factor measurement, respectively, and Miquel Truyols and collaborators of the UIB Experimental Field and Greenhouses (UIB Grant 15/2015) for their support. M. ferulaceum field pictures courtesy of Pere Fraga Arguimbau.
} 
1988, Nilsen and Bao 1990, Tinoco-Ojanguren 2008) resulting in higher intrinsic water-use efficiency $\left(\mathrm{WUE}_{\mathrm{i}}\right.$, as $P_{\mathrm{N}} / g_{\mathrm{s}}$ ) for the stem as compared to the leaf (Santiago et al. 2016). As compared to leaves, it has been suggested that the adaptive importance of green stems is higher in minimizing carbon loss through respiration rather than minimizing water loss (Berveiller et al. 2007, Ávila et al. 2014).

The Balearic species of Limonium inhabit harsh environments in saline soils in the rocky coast and marshes of the archipelago, where drought and salinity limit survivorship of most species. Due to the low plant occurrence, Limonium species are highly exposed to insolation and abrasion of the saline winds from the sea. Previous studies demonstrated important adaptations allowing to withstand severe drought conditions (Galmés et al. 2007a,b, 2017; Conesa et al. 2019). There is a large diversity in leaf size among species, and those with larger leaves have a higher growth capacity and higher water-use efficiency (Conesa et al. 2019). To further study the importance of leaves in the adaptation to the harsh environment of Limonium, it would be ideal to compare leaved and leafless Limonium species inhabiting the same environment. However, there are no leafless Limonium species in the western Mediterranean.

Myriolimon ferulaceum is a leafless species that inhabits rocky coast and marsh habitats in the Balearic Islands. This species was included within the genus Limonium (i.e. L. ferulaceum) until recently, when it was placed within a new genus based on discordant morphology, karyology, and phytochemistry (Lledó et al. 2003, 2005). As compared to Limonium plant habit, consisting in a dense and foliose subshrub cushion with seasonal reproductive branches, $M$. ferulaceum has numerous prostrate to ascendant, articulate stems up to $65 \mathrm{~cm}$ long, densely branched in the upper third (Erben 1993, Fig. 1S), that are maintained all year round constituting the body of the plant. Consequently, photosynthesis and gas exchange in this $\mathrm{C}_{3}$ species is performed by stems, which have many stomata (Fig. 2S).

Given the importance of a leaf size in the response to harsh conditions previously reported in Limonium and its coordination with Rubisco kinetics (Galmés et al. 2014, 2017; Conesa et al. 2019), in this study we aimed to understand how the leafless strategy in the close relative $M$. ferulaceum can be also relevant under the same harsh conditions. To do so, we performed an experiment growing $M$. ferulaceum plants under the same well-watered and severe water deficit conditions as in previous studies on Limonium, and measured growth, water consumption and water-use efficiency, photosynthesis and gas exchange, Rubisco kinetics, and stem anatomy traits. Results showed the importance of densely branched stem structures in substituting leaf function, and denoted the modifications in stem anatomy allowing to withstand stressful conditions.

\section{Materials and methods}

Plant growth, water treatments, water consumption, and climatic conditions: Seeds from Myriolimon ferulaceum (L.) Lledó, Erben \& M.B. Crespo were collected from natural populations in Minorca and germinated. Afterwards, ten plants were grown outdoors at the University of the Balearic Islands, individually in $3-\mathrm{L}$ pots filled with a $4: 1(\mathrm{v} / \mathrm{v})$ mixture of peat-based horticultural substrate (Prohumin-Potting Soil Klasmann-Deilmann, Projar $S A$, Valencia, Spain) and perlite (granulometry A13, Projar $S A$ ). All pots were filled to reach the same mass. Five more pots were prepared and used to calculate maximum soil water content. To do so, pots were irrigated at full capacity and left to drain plastic covered for $12 \mathrm{~h}$ into a room at $20^{\circ} \mathrm{C}$, and weighed. The soil water content at full capacity was obtained by subtracting to the latter mass the masses of the empty pot and the dry soil. The dry mass of the soil was obtained after drying it to constant mass in trays in an air-forced oven at $70^{\circ} \mathrm{C}$. Values used for calculations were the average of the five pots. The pot water content at full capacity was $2,251 \mathrm{~g}$. During the experiment, the mass of the dry soil and the empty pot was used to calculate the amount of water in any pot at any moment.

Plants were initially fertilized with slow-release fertilizer and, once a week, irrigation was performed with $50 \%$ Hoagland's solution instead of water, to prevent nutrient deficiencies. After germination, irrigation was supplied at the field capacity during the spring season (15 March to 28 June) to ensure a correct plant establishment and a minimum plant size. During the summer season (29 June to 13 September), five plants were still maintained at field capacity (WW treatment), and in the remaining five, irrigation was gradually reduced during two weeks to reach a pot water content close to $45 \%$ of field capacity, and maintained below this level during the entire experiment (WD treatment). To do so, pots of both treatments were weighted and lost water replaced every $2-3 \mathrm{~d}$. During the months with water treatments established, the pot water content ranged from 73\% (just before irrigation; 1,643 g water in pot soil) to $100 \%$ (just after irrigation; $2,251 \mathrm{~g}$ water in pot soil) in WW, and from $30 \%$ (just before irrigation; $675 \mathrm{~g}$ water in pot soil) to $45 \%$ (just after irrigation; 1,013 $\mathrm{g}$ water in pot soil) in WD (Fig. 3S). Water consumption per plant (WC) corresponds to the sum of all the masses of replaced water during the three months with water treatments established.

Climatic conditions during the experiment were those typical of Mediterranean summer, with average daily temperature varying (minimum-maximum) during the experiment between $23.6-30.6^{\circ} \mathrm{C}$ in July, $21.6-27.2^{\circ} \mathrm{C}$ in August, and $17.6-23.4^{\circ} \mathrm{C}$ in September; daily sum of PAR ranging 6,790-15,681 $\mu \mathrm{mol}$ (photon) $\mathrm{m}^{-2} \mathrm{~s}^{-1}$ in July, 6,500-14,615 $\mathrm{mol}$ (photon) $\mathrm{m}^{-2} \mathrm{~s}^{-1}$ in August, and 3,241$11,905 \mu \mathrm{mol}$ (photon) $\mathrm{m}^{-2} \mathrm{~s}^{-1}$ in September; and average air relative humidity ranging $36-65 \%$ in July, $45-74 \%$ in August, and $48-83 \%$ in September.

Growth and plant water-use efficiency measurements: At the end of the experiment, $183 \mathrm{~d}$ after germination and after $77 \mathrm{~d}$ with water treatments established, all plants were cut separating stems and roots. The root ball was submerged in water overnight to ease soil separation from the roots, and gentle combed under water tab pressure. Stem and root fractions were placed in different paper envelopes and dried to constant mass in an air-forced oven 
at $70^{\circ} \mathrm{C}$ to obtain the total plant biomass $\left(\mathrm{B}_{\mathrm{T}}\right)$. Since the leafless plant habit of $M$. ferulaceum, the ratio between root and stem biomass corresponds to the root/shoot ratio $(\mathrm{R} / \mathrm{S})$. The water-use efficiency at the whole plant level $\left(\mathrm{WUE}_{\mathrm{b}}\right.$ ) was calculated as the ratio between $\mathrm{B}_{\mathrm{T}}$ and $\mathrm{WC}$.

Stem relative water content (RWC) at mid-morning was determined as in Galmés et al. (2007a), at the same day as photosynthesis measurements and on the same or similar terminal stems used for gas exchange and chlorophyll (Chl) fluorescence. Five replicates per treatment were obtained from different individuals.

Stem gas exchange and $\mathrm{Chl} a$ fluorescence were measured simultaneously with an open infrared gas-exchange analyzer system equipped with a $2-\mathrm{cm}^{2}$ leaf chamber with a built-in fluorometer ( $\mathrm{Li}$-6400-40, Li-Cor Inc., USA). Measurements were performed from 9:00 to 12:00 h during August, i.e. two months after the onset of the drought treatment, on intact terminal stems of five individuals; clamped terminal stems were completely developed under treatment.

Gas flow was set at $250 \mu \mathrm{mol} \mathrm{mol}{ }^{-1}$ and environmental conditions in the leaf chamber consisted of a PPFD of $1,500 \mu \mathrm{mol}\left(\right.$ photon) $\mathrm{m}^{-2} \mathrm{~s}^{-1}$ (with $10 \%$ blue light), a vapor pressure deficit of $1.2-2.5 \mathrm{kPa}$, and a leaf temperature of $25^{\circ} \mathrm{C}$. After inducing steady-state photosynthesis for at least $30 \mathrm{~min}$ at an ambient $\mathrm{CO}_{2}$ concentration $\left(C_{\mathrm{a}}\right)$ of $400 \mu \mathrm{mol} \mathrm{mol}^{-1}$ (air), the photosynthesis response to varying substomatal $\mathrm{CO}_{2}$ concentration $\left(C_{\mathrm{i}}\right)$ was measured as explained in Galmés et al. (2007b). Net photosynthesis response curves to varying substomatal $\mathrm{CO}_{2}$ concentration $\left(P_{\mathrm{N}}-C_{\mathrm{i}}\right)$ consisted of 12 measurements per curve, and five $P_{\mathrm{N}}-C_{\mathrm{i}}$ were performed per treatment on different individuals. After gas-exchange measurements had been taken, the stems were sectioned and the projected area was measured by scanning it with a standard flat-bed scanner (Epson Stylus CX3600, Seiko Epson Corp., Japan), and measuring the green area on the scanned image with Image $J$ (Ambràmoff et al. 2004). Total stem surface area was determined by multiplying the projected area by $\pi$ (3.14) and divided by 2 . Corrections for the leakage of $\mathrm{CO}_{2}$ into and out of the leaf chamber of the $\mathrm{Li}-6400-40$ have been applied to all gas-exchange data, as described by Flexas et al. (2007).

Simultaneous measurements of Chl $a$ fluorescence were made at each $C_{\mathrm{a}}$ of the $P_{\mathrm{N}}-C_{\mathrm{i}}$ curve. The fluorometer was set to multiphase pulse with target intensity $=10$ and ramp depth $=40 \%$. The quantum efficiency of the PSIIdriven electron transport was determined using the equation $\Phi_{\mathrm{PSII}}=\left(\mathrm{F}_{\mathrm{m}}{ }^{\prime}-\mathrm{F}_{\mathrm{s}}\right) / \mathrm{F}_{\mathrm{m}}{ }^{\prime}$, where $\mathrm{F}_{\mathrm{s}}$ is the steady-state fluorescence in the light [PPFD of 1,500 $\mu \mathrm{mol}$ (photon) $\mathrm{m}^{-2} \mathrm{~s}^{-1}$ ] and $\mathrm{F}_{\mathrm{m}}{ }^{\prime}$ the maximum fluorescence obtained with a light-saturating pulse $\left[8,500 \mu \mathrm{mol}\right.$ (photon) $\left.\mathrm{m}^{-2} \mathrm{~s}^{-1}\right]$. As $\Phi_{\text {PSII }}$ represents the number of electrons transferred per photon absorbed by PSII, the rate of electron transport $(J)$ can be calculated as: $J=\Phi_{\text {PSII }} \times$ PPFD $\times \alpha \times \beta$, where $\alpha$ is the leaf absorbance and $\beta$ is the distribution of absorbed energy between the two photosystems. The product $\alpha \times \beta$ was determined from the relationship between $\Phi_{\mathrm{PSII}}$ and
$\Phi_{\mathrm{CO} 2}$ obtained by varying $C_{\mathrm{a}}$ under nonphotorespiratory conditions in a nitrogen atmosphere containing less than $2 \%$ (v/v) $\mathrm{O}_{2}$ (Martins et al. 2013). Values of $\alpha \times \beta$ averaged 0.34 with insignificant differences between treatments.

From combined gas-exchange and Chl $a$ fluorescence measurements, mesophyll conductance to $\mathrm{CO}_{2}\left(g_{\mathrm{m}}\right)$ was estimated at each $C_{\mathrm{i}}$ according to Harley et al. (1992) as: $g_{\mathrm{m}}=P_{\mathrm{N}} /\left\{C_{\mathrm{i}}-\Gamma^{*}\left[J+8\left(P_{\mathrm{N}}+R_{\mathrm{D}}\right)\right] /\left[\left(J-4\left(P_{\mathrm{N}}+R_{\mathrm{D}}\right)\right]\right\}\right.$. Half of the rate of mitochondrial respiration in the darkness $\left(R_{\mathrm{D}}\right)$ was used here as a proxy for the rate of mitochondrial respiration in the light $\left(R_{\mathrm{L}}\right) . R_{\mathrm{D}}$ was measured at predawn (from 4:00 to 6:00 h) using the Li-6400-40. Measuring conditions in the leaf cuvette were: $C_{\mathrm{a}}$ of $400 \mu \mathrm{mol}$ $\mathrm{mol}^{-1}$ (air), leaf temperature of $25^{\circ} \mathrm{C}$, and vapor pressure deficit of 1.0-1.5 $\mathrm{kPa}$. The chloroplast $\mathrm{CO}_{2}$ compensation point $\left(\Gamma^{*}\right)$ was calculated from the in vitro Rubisco specificity factor $\left(S_{\mathrm{c} / \mathrm{o}}\right)$ value at $25^{\circ} \mathrm{C}$ (obtained as indicated below) and the ambient oxygen concentration $\left(\mathrm{O}_{\mathrm{A}} ; 210,000\right.$

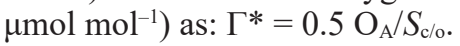

$P_{\mathrm{N}}-C_{\mathrm{i}}$ curves were transformed into $P_{\mathrm{N}} v s$. chloroplastic $\mathrm{CO}_{2}$ concentration $\left(C_{\mathrm{c}}\right)$ curves using the estimated values of $g_{\mathrm{m}}$ at each $C_{\mathrm{i}}$. From $P_{\mathrm{N}}-C_{\mathrm{c}}$ curves, the maximum velocity of carboxylation $\left(V_{\text {cmax }}\right)$ and the maximum capacity for electron transport rate $\left(J_{\max }\right)$ were calculated as in Bernacchi et al. (2002), but using the values for the kinetic parameters of Rubisco for $M$. ferulaceum, obtained as indicated below. The Farquhar, von Caemmerer, and Berry model (Farquhar et al. 1980) was fitted to the data by applying iterative curve-fitting (minimum least square difference) using Microsoft Excel Solver tool.

The in vivo photosynthetic carboxylation efficiency was inferred from the $P_{\mathrm{g}} / C_{\mathrm{c}}$ ratio, being $P_{\mathrm{g}}$ the gross $\mathrm{CO}_{2}$ assimilation rate, calculated as the sum of $P_{\mathrm{N}}$ and $R_{\mathrm{L}}$.

Analysis of quantitative limitations of photosynthetic $\mathrm{CO}_{2}$ assimilation: The quantitative limitation analysis of Grassi and Magnani (2005), as applied in Tomàs et al. (2013), was used to separate the controls on $P_{\mathrm{N}}$ resulting from limited stomatal conductance $\left(l_{\mathrm{s}}\right)$, mesophyll diffusion $\left(l_{\mathrm{m}}\right)$, and photosynthetic capacity $\left(l_{\mathrm{b}}\right)$ under WW and WD. The limitations of the different components, $l_{\mathrm{s}}, l_{\mathrm{m}}$, and $l_{\mathrm{b}}$ $\left(l_{\mathrm{s}}+l_{\mathrm{m}}+l_{\mathrm{b}}=1\right)$ were calculated as: $l_{\mathrm{s}}=\left[\left(g_{\mathrm{tot}} / g_{\mathrm{s}}\right)\left(\delta P_{\mathrm{N}} / \delta C_{\mathrm{c}}\right)\right] /$ $\left[g_{\text {tot }}+\left(\delta P_{\mathrm{N}} / \delta C_{\mathrm{c}}\right)\right] ; l_{\mathrm{m}}=\left[\left(g_{\text {tot }} / g_{\mathrm{m}}\right)\left(\delta P_{\mathrm{N}} / \delta C_{\mathrm{c}}\right)\right] /\left[g_{\text {tot }}+\left(\delta P_{\mathrm{N}} / \delta C_{\mathrm{c}}\right)\right] ;$ $l_{\mathrm{b}}=g_{\text {tot }} /\left[g_{\text {tot }}+\left(\delta P_{\mathrm{N}} / \delta C_{\mathrm{c}}\right)\right]$; where $g_{\mathrm{s}}$ is the stomatal conductance to $\mathrm{CO}_{2}, g_{\mathrm{m}}$ is the mesophyll conductance according to Harley et al. (1992), and $g_{\text {tot }}$ is the total conductance to $\mathrm{CO}_{2}$ from ambient air to chloroplasts. The $g_{\text {tot }}$ was obtained as the sum of mesophyll and stomatal conductance to $\mathrm{CO}_{2}$ considering that both are in series $\left(1 / g_{\text {tot }}=1 / g_{\mathrm{s}}+1 / g_{\mathrm{m}}\right)$. Five curves were used per treatment, and average estimates of the limitations were calculated per treatment.

Anatomical measurements of photosynthetic stems: From stems previouslyused in gas-exchange measurements, 8-12 fragments of $c a$. 2-3 mm were cut and immediately vacuum fixed in a phosphate buffer $(0.1 \mathrm{M}$ at $\mathrm{pH} 7.2$, $4 \%$ glutaraldehyde and 2\% paraformaldehyde), during $48 \mathrm{~h}$. Afterwards, samples were washed tree times with $0.01 \mathrm{M} \mathrm{PBS}$ at $\mathrm{pH} 7.4$ for $15 \mathrm{~min}$, and stained/fixed with $\mathrm{OsO}_{4}$ in $0.01 \mathrm{M} \mathrm{PBS}$ at $\mathrm{pH} 7.4$ for $2 \mathrm{~h}$ at $4^{\circ} \mathrm{C}$. A further 
wash with PBS at $\mathrm{pH} 7.4$ for 15 min was made, previous to dehydration with an increasing gradient of ethanol at room temperature $(50,70,95$, and $100 \%$; for a minimum $30 \mathrm{~min}$ each). Dehydrated fragments were included in Spurr's resin following fabricant prescription (http://www. emsdiasum.com/microscopy/technical/datasheet/14300. aspx). Semi-thin cross sections of $1 \mathrm{~mm}$ wide were performed using a diamond blade (DIATOME Histo $45^{\circ}$ ) with an ultramicrotome (Ultratome Nova, $L K B$, Bromma), stained with toluidine blue and mounted on microscope slides. Images were taken at $200 \times$ magnification with the optic microscope Olympus Provis AX70 equipped with an Olympus Camedia C-2000 Z camera (Olympus Optical Co., Ltd., Tokyo, Japan).

Anatomical measurements were performed in three different plants per water treatment with Image $J$ (Ambràmoff et al. 2004), dividing each section in four equal portions (i.e. $1 / 4$ portions) that were analyzed separately, resulting in $n=12$ per plant for area measurements, namely, mesophyll airspaces (Mes $\left.{ }^{\mathrm{air}}\right)$, mesophyll cells $\left(\mathrm{Mes}^{\mathrm{cell}}\right)$, sclereids ( $\mathrm{Scl}$ ), and vascular tissue (Vas); whereas total mesophyll area $\left(\mathrm{Mes}^{\text {total }}\right)$ was the sum of Mes ${ }^{\text {air }}$ and $\mathrm{Mes}^{\text {cell. }}$. To perform area measurements, images were previously modified with Adobe Photoshop CS5 (v. 12.1, Adobe, San José, CA, USA) as in Fig. $1 A$, allowing a precise selection and separation of the different parts analyzed. Linear measurements included maximum stem diameter of the cross section and epidermis thickness (Ep), the latter being measured in four equidistant points for each $1 / 4$ portion, considering their average as the single value per $1 / 4$ portion.

Rubisco catalytic characterization: Rates of Rubisco ${ }^{14} \mathrm{CO}_{2}$-fixation using fresh leaf protein extract were measured in 7-mL septum-capped scintillation vials, containing reaction buffer (yielding final concentrations of $100 \mathrm{mM}$ Bicine- $\mathrm{NaOH}, \mathrm{pH}$ 8.0, $20 \mathrm{mM} \mathrm{MgCl}, 0.4 \mathrm{mM}$ $\mathrm{RuBP}$, and about $100 \mathrm{~W}$-A units of carbonic anhydrase) and one of nine different concentrations of $\mathrm{CO}_{2}(0$ to $80 \mu \mathrm{M}$, each with a specific radioactivity of $3.7 \times 1,010 \mathrm{~Bq} \mathrm{~mol}^{-1}$ ), each at two concentrations of $\mathrm{O}_{2}[0$ and $21 \%(\mathrm{v} / \mathrm{v})]$, as described previously (Galmés et al. 2014). Assays (1.0 mL of the total volume) were started by the addition of activated plant extract, and the maximum velocity for carboxylase activity $\left(V_{\text {cmax }}\right)$, together with the Michaelis-Menten constant $\left(K_{\mathrm{m}}\right)$ for $\mathrm{CO}_{2}\left(K_{\mathrm{c}}\right)$ determined from the fitted data. The $K_{\mathrm{m}}$ for the oxygenase activity was calculated from the relationship $K_{\mathrm{c},(21 \% \mathrm{O} 2)}=K_{\mathrm{c},(0 \% \mathrm{O} 2)} \cdot\left(1+\left[\mathrm{O}_{2}\right] / K_{\mathrm{o}}\right)$. The $\left[\mathrm{O}_{2}\right]$ was assumed to be $265 \mu \mathrm{M}$, but corrected for partial pressure by taking account of the atmospheric pressure and water saturated vapor pressure. Replicate measurements $(n=3)$ were made using protein preparations from four different stems of different individuals grown under WW conditions. For each sample, the maximum rate of carboxylation $\left(k_{\text {cat }}^{\mathrm{c}}\right)$ was extrapolated from the corresponding $V_{\max }$ value after allowance was made for the Rubisco active site concentration, as determined by $\left[{ }^{14} \mathrm{C}\right] \mathrm{CPBP}$ binding (Yokota and Canvin 1985). Rubisco $\mathrm{CO}_{2} / \mathrm{O}_{2}$ specificity $\left(S_{\mathrm{c} / \mathrm{o}}\right)$ was measured as described (Galmés et al. 2005) using enzyme purified by PEG precipitation and ion exchange chromatography, and the values given for each species were the mean of five to ten repeated determinations. The maximum rate of oxygenation $\left(k_{\text {cat }}^{0}\right)$ was calculated using the equation $S_{\mathrm{c} / \mathrm{o}}=\left(k_{\text {cat }}^{\mathrm{c}} / K_{\mathrm{c}}\right) /\left(k_{\text {cat }}^{0} / K_{\mathrm{o}}\right)$. All kinetic measurements were performed at $25^{\circ} \mathrm{C}$.

The concentration of active Rubisco sites was calculated dividing the in vivo $V_{\text {cmax }}$ by the in vitro $k_{\text {cat }}^{\mathrm{c}}$ measured for each species.

Statistical analysis: One-way analysis of variance (ANOVA) was performed to reveal the differences between treatments in the studied parameters. The univariate general linear model for unbalanced data (Proc. GLM) was applied, with type III sum of squares, and significant differences were revealed by Duncan's post-hoc tests (at $P<0.05)$ using IBM SPSS Statistics 20 software package (SPSS Inc., Chicago, IL, USA). The relationships among the parameters were tested with the square of the correlation coefficient observed for linear regressions using the tool implemented in SigmaPlot 11.0 (Sigma, St Louis, MO, USA). All statistical tests were considered significant at $P<0.05$.

\section{Results}

Growth and water consumption: As compared to wellwatered conditions (WW), long-term exposure to severe water deficit conditions (WD) had a dramatic effect on total plant biomass $\left(\mathrm{B}_{\mathrm{T}}\right)$ in $M$. ferulaceum, with more than 4-fold reduction (Table 1). The water consumption during the water treatments application (WC) was 6-fold lower under WD and, thus, proportionally higher than $\mathrm{B}_{\mathrm{T}}$ reduction. Consequently, water-use efficiency at the whole plant level (WUE $\mathrm{W}_{\mathrm{b}}$, as $\mathrm{B}_{\mathrm{T}} / \mathrm{WC}$ ) might be on average higher under WD than under WW conditions, but differences between treatments were insignificant (Table 1). Plants under WD had 2-fold higher root/shoot ratio $(\mathrm{R} / \mathrm{S})$ than that of WW plants and, thus, this species responded to severe water deficit by a notorious increase in the proportion of root biomass (Table 1). The relative water content in the stems (RWC) was also significantly affected by the water deficit, with a $12 \%$ lower value under WD (Table 1 ).

Stem anatomy: Stems under WD were significantly thinner than that under WW, with the stem section and

Table 1. Growth and water-use parameters for Myriolimon ferulaceum grown under field capacity (WW) and severe water deficit (WD). $\mathrm{B}_{\mathrm{T}}$ - total plant biomass; R/S - root to shoot ratio; $\mathrm{WC}$ - water consumed during the period between 29 June and 13 September; $W_{U E}$ - water-use efficiency at the whole plant level; RWC - stem relative water content. ANOVA P-value is indicated for each parameter. Data are means $\pm \operatorname{SE}(n=5)$.

\begin{tabular}{lllr}
\hline Parameter & WW & WD & $P$-value \\
\hline $\mathrm{B}_{\mathrm{T}}[\mathrm{g}]$ & $11.5 \pm 0.7$ & $2.7 \pm 0.4$ & $<0.001$ \\
$\mathrm{R} / \mathrm{S}$ & $0.53 \pm 0.06$ & $1.07 \pm 0.21$ & $<0.001$ \\
$\mathrm{WC}\left[\mathrm{L} \mathrm{plant}^{-1}\right]$ & $10.6 \pm 1.3$ & $1.8 \pm 0.1$ & $<0.001$ \\
$\mathrm{WUE}_{\mathrm{b}}\left[\mathrm{g} \mathrm{L}^{-1}\right]$ & $0.80 \pm 0.10$ & $0.71 \pm 0.08$ & 0.243 \\
RWC $[\%]$ & $77 \pm 1$ & $65 \pm 1$ & $<0.001$ \\
\hline
\end{tabular}


the stem diameter being 20 and $10 \%$ smaller, respectively (Fig. 1A, Table 2). Considering the components in the stem section, all were reduced except the area of the total mesophyll (Mes ${ }^{\text {total }}$ ) and the area of the mesophyll airspaces $\left(\mathrm{Mes}^{\mathrm{air}}\right)$. Therefore, the latter two components proportionally increased under WD to remain similar between treatments despite of the reduction on the total stem thickness under WD. This proportional increase in Mes $^{\text {total }}$ and $\mathrm{Mes}^{\mathrm{air}}$ was at expenses of a proportionally higher reduction in the mesophyll cells $\left(\mathrm{Mes}^{\text {cell }}\right)$, sclereids (Scl), and vascular tissue (Vas), but not epidermis (Ep), which was thicker under WD (Fig. 1B, Table 2).

Photosynthesis and gas exchange: The WD treatment had also an important effect on the photosynthesis performance of $M$. ferulaceum, with differences between treatments in
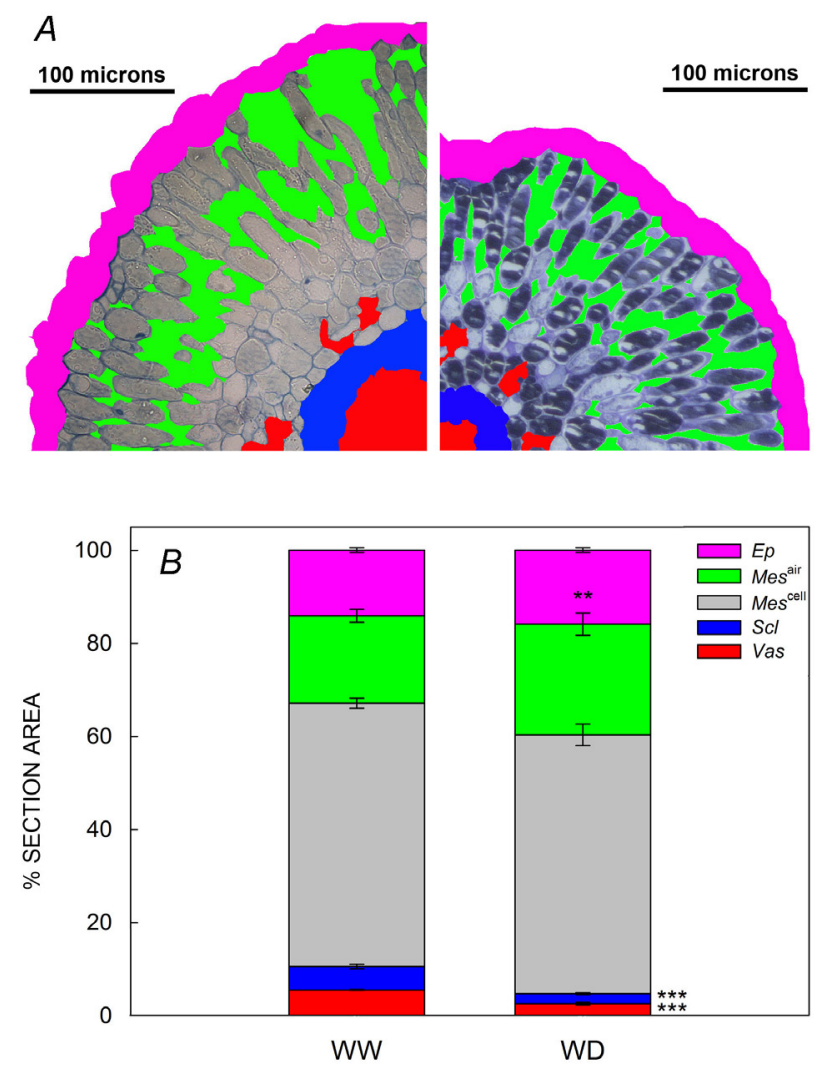

Fig. 1. Anatomical differences between the well-watered (WW) and severe water deficit (WD) treatments of Myriolimon ferulaceum plants. A shoot section was measured from three different plants per treatment. Each section was divided into four pieces that were measured separately, thus $n=12$ for all the parameters. Thicknesses were measured in four equidistant points in each of the pieces and values were averaged to consider a single value per piece. (A) Piece ( $1 / 4)$ of the section for WW (left) and WD (right), indicating the different components in colors: epidermis (Ep, purple), mesophyll airspaces (Mes ${ }^{\text {air }}$, green), mesophyll cells (Mes ${ }^{\text {cell }}$, grey/uncolored), sclereids (Scl, blue), and vascular tissue (Vas, red). (B) Percent of the total section for the different components. Correspondence of components and colors as in $(A)$. Percent differences between treatments by one-way $A N O V A$ are indicated with asterisks in the WD column $\left({ }^{* * *} P<0.001,{ }^{* *} P<0.01,{ }^{*} P<0.05\right)$.
11 the measured parameters (Table 3). There was a 3.6-fold lower stem $P_{\mathrm{N}}$ under $\mathrm{WD}$ as compared to $\mathrm{WW}$, and a significant relationship was observed between $P_{\mathrm{N}}$ and $\mathrm{B}_{\mathrm{T}}$ $\left(R^{2}=0.76, P<0.001\right.$; data not shown). There was also a 6.3-fold lower stem $g_{\mathrm{s}}$ under WD, very similar to the 6-fold difference in WC between treatments. A significant relationship was also observed between $g_{\mathrm{s}}$ and WC $\left(R^{2}=\right.$ $0.59, P<0.001$; data not shown). Different from $\mathrm{WUE}_{\mathrm{b}}$, the intrinsic water-use efficiency ( $\mathrm{WUE}_{\mathrm{i}}$, as $P_{\mathrm{N}} / g_{\mathrm{s}}$ ) was 1.7 -fold higher under WD as compared to WW (Table 3 ).

The mesophyll conductance $\left(g_{\mathrm{m}}\right)$ was 2.3 -fold lower under WD which, added up to the difference in $g_{\mathrm{s}}$, resulted in a 4-fold lower $g_{\text {tot }}$ under WD (Table 3 ). The $g_{\mathrm{m}} / g_{\mathrm{s}}$ ratio increased from 1.3 under WW to 3.1 under WD (Table 3 ), and positively correlated with $\mathrm{WUE}_{\mathrm{i}}$ under both treatments (WW, $R^{2}=0.932 ; \mathrm{WD}, R^{2}=0.887 ; P<0.001$ in both cases) and also considering both treatments together (Fig. 2), denoting a similar scale-up of $g_{\mathrm{m}} / g_{\mathrm{s}}$ and $\mathrm{WUE}_{\mathrm{i}}$ under WD as compared to WW.

The $\mathrm{CO}_{2}$ concentration at the chloroplast stroma $\left(C_{\mathrm{c}}\right)$ was 1.6-fold lower under WD, being responsible for the lower $P_{\mathrm{N}}$ values in this treatment (Table 3 ). When considering the gross photosynthesis $\left(P_{\mathrm{g}}\right)$, the photosynthetic efficiency $\left(P_{\mathrm{g}} / C_{\mathrm{c}}\right)$ was 2-fold lower under WD, whereas photorespiration (considering the electron transport rate, i.e. ETR/ $P_{\mathrm{g}}$ ), was 1.6-fold higher under WD (Table 3). The maximum rate of photosynthetic electron transport $\left(J_{\max }\right)$ was also severely depressed under WD.

Rubisco-related traits and Rubisco kinetic properties: There were differences in the Rubisco active sites between treatments, being 2.1-fold lower under WD, and agreeing with the 2.1-fold lower maximum rate of Rubisco carboxylation velocity $\left(V_{\text {cmax }}\right)$ under this treatment (Table 3 ).

Regarding the catalytic parameters of Rubisco from $M$. ferulaceum (Table 4), the maximum rates of carboxylation $\left(k_{\text {cat }}^{\mathrm{c}}\right)$ and oxygenation $\left(k_{\text {cat }}^{\mathrm{o}}\right)$ were $2.9 \mathrm{~s}^{-1}$ and $1.4 \mathrm{~s}^{-1}$, respectively. The Michaelis-Menten constants affinity for $\mathrm{CO}_{2}\left(K_{\mathrm{c}}\right)$ and $\mathrm{O}_{2}\left(K_{\mathrm{o}}\right)$ were 7.4 and $466 \mu \mathrm{M}$, respectively, and the specificity factor $\left(S_{\mathrm{c} / \mathrm{o}}\right)$ was $102.5 \mathrm{~mol} \mathrm{~mol}^{-1}$.

The quantitative limitation analysis of photosynthetic $\mathrm{CO}_{2}$ assimilation showed a similar importance of the three limitations under WW. Under WD, the biochemical limitation $\left(l_{\mathrm{b}}\right)$ decreased and stomatal conductance limitation $\left(l_{\mathrm{s}}\right)$ increased as compared to WW (Fig. 3). In spite of the proportional changes in the limitations components, $P_{\mathrm{N}}$ correlated with both $g_{\text {tot }}$ and $V_{\text {cmax }}$ (Fig. 4).

\section{Discussion}

Leafless plant habit is frequently considered an adaptive strategy to cope with severe drought conditions (e.g. Nilsen and Sharifi 1997, Galmés et al. 2005, Correia and Ascensão 2017). However, similar to leaved species, stems in the leafless $M$. ferulaceum suffered important modifications to withstand stressful conditions. As compared to the close relative and leaved Limonium species, the leafless strategy in $M$. ferulaceum presented higher limitations to overcome severe water deficit. 
Table 2. Anatomical differences between the well-watered (WW) and severe water deficit (WD) treatments for the whole cross section, and for epidermis (Ep), mesophyll airspaces (Mes ${ }^{\text {air }}$, mesophyll cells (Mes ${ }^{\text {cell }}$ ), sclereids (Scl), and vascular tissue (Vas) of Myriolimon ferulaceum. A shoot section was measured from three different plants per treatment. Values are averages with SE. Each section was divided in four pieces that were measured separately, thus $n=12$ for all the parameters. Differences between treatments by one-way $A N O V A$ are indicated ( $P$-values). See Fig. 1 for a reference.

\begin{tabular}{lllr}
\hline & WW & WD & $P$-value \\
\hline Cross section area $\left[\mu \mathrm{m}^{2}\right]$ & $272,307 \pm 11,037$ & $218,874 \pm 7,168$ & 0.001 \\
Cross section maximum diameter $[\mu \mathrm{m}]$ & $633.5 \pm 11.9$ & $569.1 \pm 13.5$ & 0.002 \\
Ep thickness & $22.0 \pm 0.6$ & $24.0 \pm 0.7$ & 0.032 \\
Mes $^{\text {total }}$ area $\left[\mu \mathrm{m}^{2}\right]$ & $206,319 \pm 11,065$ & $181,290 \pm 6,704$ & 0.124 \\
Mes $^{\text {air }}$ area $\left[\mu \mathrm{m}^{2}\right]$ & $52,327 \pm 5,354$ & $55,487 \pm 7,304$ & 0.712 \\
Mes $^{\text {cell }}$ area $\left[\mu \mathrm{m}^{2}\right]$ & $153,992 \pm 7,243$ & $125,802 \pm 4,302$ & 0.020 \\
Scl area $\left[\mu \mathrm{m}^{2}\right]$ & $13,135 \pm 953$ & $4,448 \pm 265$ & $<0.001$ \\
Vas area $\left[\mu \mathrm{m}^{2}\right]$ & $14,730 \pm 426$ & $5,050 \pm 576$ & $<0.001$ \\
\hline
\end{tabular}

Table 3. Average values for the main photosynthetic parameters in Myriolimon ferulaceum under field capacity (WW) and severe water deficit (WD) treatments. Net $\mathrm{CO}_{2}$ assimilation rate $\left(P_{\mathrm{N}}\right)$, stomatal, mesophyll, and total leaf conductances $\left(g_{\mathrm{s}}, g_{\mathrm{m}}, g_{\text {tot }}\right.$, respectively), intrinsic water-use efficiency $\left(\mathrm{WUE}_{\mathrm{i}}\right), \mathrm{CO}_{2}$ concentration in the chloroplast $\left(C_{\mathrm{c}}\right), \mathrm{CO}_{2}$ assimilation rate $\left(P_{\mathrm{g}}\right)$, and electron transport rate (ETR) were obtained from steady state measurements at a PPFD of $1,500 \mu \mathrm{mol}\left(\right.$ photon) $\mathrm{m}^{-2} \mathrm{~s}^{-1}$, with a leaf temperature of $25^{\circ} \mathrm{C}$, and a $\mathrm{CO}_{2}$ concentration in the chamber of $400 \mu \mathrm{mol} \mathrm{mol}^{-1}$. Maximum velocity of carboxylation $\left(V_{\text {cmax }}\right)$ and maximum electron transport rate $\left(J_{\max }\right)$ were estimated from $P_{\mathrm{N}}-C_{\mathrm{c}}$ curves. The active Rubisco sites were calculated dividing in vivo $V_{\mathrm{cmax}}$ by the in vitro maximum rate of carboxylation $\left(k_{\text {cat }}^{\mathrm{c}}\right)$. ANOVA P-value is indicated for each parameter. Data are means $\pm \operatorname{SE}(n=5)$. All area-based parameters were corrected to account for the semicircular surface of the stems, dividing the measured value by $\pi / 2$.

\begin{tabular}{lllr}
\hline Parameter & WW & WD & $P$-value \\
\hline$P_{\mathrm{N}}\left[\mu \mathrm{mol} \mathrm{m}{ }^{-2} \mathrm{~s}^{-1}\right]$ & $14.1 \pm 1.5$ & $3.9 \pm 0.3$ & $<0.001$ \\
$g_{\mathrm{s}}\left[\mathrm{mol}\left(\mathrm{H}_{2} \mathrm{O}\right) \mathrm{m}^{-2} \mathrm{~s}^{-1}\right]$ & $0.19 \pm 0.03$ & $0.03 \pm 0.01$ & $<0.001$ \\
$g_{\mathrm{m}}\left[\mathrm{mol} \mathrm{m}^{-2} \mathrm{~s}^{-1}\right]$ & $0.14 \pm 0.02$ & $0.06 \pm 0.01$ & 0.001 \\
$g_{\text {tot }}\left[\mathrm{mol} \mathrm{m}^{-2} \mathrm{~s}^{-1}\right]$ & $0.08 \pm 0.01$ & $0.02 \pm 0.01$ & $<0.001$ \\
$\mathrm{WUE}_{\mathrm{i}}\left[\mu \mathrm{mol} \mathrm{mol}^{-1}\right]$ & $78 \pm 5$ & $135 \pm 5$ & $<0.001$ \\
$g_{\mathrm{m}} / g_{\mathrm{s}}\left[\mathrm{mol}\left(\mathrm{CO}_{2}\right) \mathrm{mol}^{-1}\left(\mathrm{CO}_{2}\right)\right]$ & $1.3 \pm 0.2$ & $3.1 \pm 0.5$ & 0.012 \\
$C_{\mathrm{c}}\left[\mu \mathrm{mol} \mathrm{mol}^{-1}\right]$ & $151 \pm 4$ & $94 \pm 6$ & $<0.001$ \\
$P_{\mathrm{g}} / C_{\mathrm{c}}\left[\mathrm{mol} \mathrm{m}^{-2} \mathrm{~s}^{-1}\right]$ & $0.10 \pm 0.01$ & $0.05 \pm 0.01$ & $<0.001$ \\
$\mathrm{ETR} / P_{\mathrm{g}}$ & $8.1 \pm 0.1$ & $12.6 \pm 0.9$ & 0.001 \\
$V_{\text {cmax }}\left[\mu \mathrm{mol} \mathrm{m}^{-2} \mathrm{~s}^{-1}\right]$ & $75.5 \pm 7.6$ & $35.3 \pm 1.0$ & $<0.001$ \\
$J_{\max }\left[\mu \mathrm{mol} \mathrm{m} \mathrm{s}^{-1}\right]$ & $125.8 \pm 11.9$ & $53.1 \pm 2.1$ & $<0.001$ \\
Active Rubisco sites $\left[\mu \mathrm{mol} \mathrm{m}{ }^{-2}\right]$ & $26.0 \pm 2.6$ & $12.2 \pm 0.3$ & $<0.001$ \\
\hline
\end{tabular}

The adaptation of $M$. ferulaceum to severe water shortage resulted in dramatic reductions of WC (6-fold) and $\mathrm{B}_{\mathrm{T}}$ (4-fold) but with no significant differences in $\mathrm{WUE}_{\mathrm{b}}$ (Table 1). The latter could indicate that this leafless species did not trigger mechanisms improving biomass produced per unit water consumed under harsh conditions. However, WD plants had a 2-fold higher R/S (Table 1). Proportionally larger roots as compared to shoots would allow higher soil exploration, and higher root biomass per unit stem - transpiring - biomass. A similar WUE between treatments achieved through a proportionally lower photosynthetic biomass indicates that morpho-physiological adaptations increasing photosynthetic efficiency took place in the WD stems.

The severe water shortage entailed a ca. 6-fold reduction of $g_{\mathrm{s}}$ under WD (Table 3 ). As a result, Rubisco had to operate at lower $C_{\mathrm{c}}$, which imposed a limitation to maximum $P_{\mathrm{N}}$ and resulted in lower photosynthetic efficiency
$\left(P_{\mathrm{g}} / C_{\mathrm{c}}\right)$ (Table 3). However, WUE $\mathrm{W}_{\mathrm{i}}$ was 1.7 -fold higher under WD. This, together with the 2.3 -fold higher $g_{\mathrm{m}}$ and 4-fold higher $g_{\text {tot }}$ (Table 3), and the tight control of $P_{\mathrm{N}}$ driven by $g_{\text {tot }}$ (Fig. $4 A$ ), indicated that the morphophysiological adaptations under WD improved $\mathrm{CO}_{2}$ diffusion per unit water transpired. Changes in $\mathrm{WUE}_{\mathrm{i}}$ were positively correlated with the $g_{\mathrm{m}} / g_{\mathrm{s}}$ ratio (Fig. 2), which increased from 1.3 under WW to 3.1 under WD (Table 3). The WD stems were thinner, with a $20 \%$ reduction of the stem section area through a decrease of Scl, Vas, and $\mathrm{Mes}^{\text {cell }}$, but maintaining Mes ${ }^{\text {total }}$ and $\mathrm{Mes}^{\text {air }}$ areas similar to those in WW, corresponding to a proportional increase of mesophyll airspaces under WD (Fig. 1, Table 2). Increase of airspaces is a common mechanism leading to increased $g_{\mathrm{m}}$, because of higher access of the mesophyll cells to $\mathrm{CO}_{2}$ (Flexas et al. 2013, 2016; Galmés et al. 2013). Also, it would be expected that thinner stems under WD might have lower $\mathrm{WUE}_{\mathrm{i}}$ because of lower proportion of 




Fig. 2. The relationship between mesophyll and stomatal conductances $\left(g_{\mathrm{m}} / g_{\mathrm{s}}\right)$ and the intrinsic water-use efficiency $\left(\mathrm{WUE}_{\mathrm{i}}\right)$ of Myriolimon ferulaceum plants. Filled black circles represent well-watered (WW) plants and empty circles represent severe water deficit (WD) plants. The regression line corresponds to both treatments together. Results are similar when considering treatments separately $\left(\mathrm{WW}, R^{2}=0.932 ; \mathrm{WD}, R^{2}=0.887 ; P<0.001\right.$ in both cases).

Table 4. Rubisco kinetic parameters at $25^{\circ} \mathrm{C}$ for Myriolimon ferulaceum. Rubisco kinetic parameters describe the MichaelisMenten constants for $\mathrm{CO}_{2}\left(K_{\mathrm{c}}\right)$ and $\mathrm{O}_{2}\left(K_{\mathrm{o}}\right)$, maximum rate of carboxylation $\left(k_{\text {cat }}^{\mathrm{c}}\right)$ and carboxylation catalytic efficiency $\left(k_{\text {cat }}^{\mathrm{c}} / K_{\mathrm{c}}\right)$, specificity factor $\left(S_{\mathrm{c} / \mathrm{o}}\right)$, maximum rate of oxygenation $\left(k_{\text {cat }}^{0}\right)$, and oxygenation catalytic efficiency $\left(k_{\text {cat }}^{0} / K_{\mathrm{o}}\right)$. Data are means $\pm \mathrm{SE}(n=3)$. The maximum rate of oxygenation $\left(k_{\text {cat }}^{\mathrm{o}}\right)$ was calculated using the equation $S_{\mathrm{c} / \mathrm{o}}=\left(k_{\text {cat }}^{\mathrm{c}} / K_{\mathrm{c}}\right) /\left(k_{\text {cat }}^{\mathrm{o}} / K_{\mathrm{o}}\right)$.

\begin{tabular}{ll}
\hline Parameter & Average \pm SE \\
\hline$K_{\mathrm{c}}[\mu \mathrm{M}]$ & $7.4 \pm 0.2$ \\
$K_{\mathrm{c}, \text { air }}[\mu \mathrm{M}]$ & $13.4 \pm 1.9$ \\
$K_{\mathrm{o}}[\mu \mathrm{M}]$ & $377 \pm 44$ \\
$k_{\text {cat }}^{\mathrm{c}}\left[\mathrm{s}^{-1}\right]$ & $2.9 \pm 0.2$ \\
$k_{\text {cat }}^{\mathrm{c}} / K_{\mathrm{c}}\left[\mathrm{s}^{-1} \mu \mathrm{M}^{-1}\right]$ & $0.39 \pm 0.04$ \\
$S_{\mathrm{c} / \mathrm{o}}\left[\mathrm{mol} \mathrm{mol}^{-1}\right]$ & $102.5 \pm 1.8$ \\
$k_{\text {cat }}^{\mathrm{o}}\left[\mathrm{s}^{-1}\right]$ & $1.4 \pm 0.4$ \\
$k_{\text {cat }}^{\mathrm{o}} / K_{\mathrm{o}}\left[\mathrm{s}^{-1} \mu \mathrm{M}^{-1}\right]$ & $2.36 \pm 0.71$ \\
\hline
\end{tabular}

photosynthetic mesophyll cells (i.e. volume-related) per unit transpiring surface (i.e. area-related). This can be related at least to three reasons. First, maximization of $P_{\mathrm{N}}$ vs. light penetration into thicker stems (Pfanz et al. 2002), i.e. thinner stems may enhance maximum $P_{\mathrm{N}}$ in most mesophyll cells. Second, the reduction in vascular tissue under WD may limit water availability for outermost cells in thicker stems. It has been demonstrated that the widely known coordination between hydraulic conductance and $P_{\mathrm{N}}$ in leaves (e.g. Scoffoni et al. 2016) also occurs in photosynthetic stems (Ávila-Lovera et al. 2017). Third, a reduction in sclereids under WD may limit plant ability to sustain stems and thus, forcing stems to be thinner.

Agreeing with the importance of the $g_{\mathrm{m}} / g_{\mathrm{s}}$ ratio in explaining $\mathrm{WUE}_{\mathrm{i}}$ improvement (Fig. 2), the quantitative limitation analysis of photosynthetic $\mathrm{CO}_{2}$ assimilation

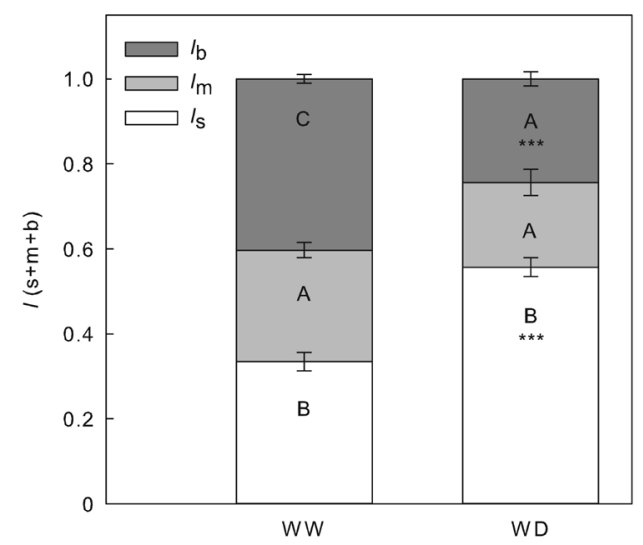

Fig. 3. Quantitative limitation analysis of photosynthetic $\mathrm{CO}_{2}$ assimilation of Myriolimon ferulaceum plants under field capacity (WW) and severe water deficit (WD) treatments. The stomatal $\left(l_{\mathrm{s}}\right)$, mesophyll $\left(l_{\mathrm{m}}\right)$, and biochemical $\left(l_{\mathrm{b}}\right)$ limitations of photosynthetic assimilation are shown for each treatment. Values are means $\pm \operatorname{SE}(n=5)$. Different letters denote statistically significant differences $(P<0.05)$ between limitations within each water treatment by Tukey's post-hoc test. Asterisks in WD mean significant difference between water treatments at ${ }^{*} P \leq 0.05$, ${ }^{* *} P \leq 0.01$ or ${ }^{* * *} P \leq 0.001$.

(Fig. 3) showed that the main limitation under WD was stomatal conductance $\left(l_{\mathrm{s}}\right)$, with a similar importance of mesophyll diffusion $\left(l_{\mathrm{m}}\right)$ and biochemistry $\left(l_{\mathrm{b}}\right)$. On the contrary, under WW the most restricting factor was biochemistry and the least mesophyll diffusion (Fig. 3). Predominance of biochemical limitation under nonstressing conditions and stomatal limitation under drought is a common pattern in angiosperms from arid and semiarid habitats like the Mediterranean (Tomàs et al. 2013, Flexas et al. 2014, Carriquí et al. 2015), and particularly in the Mediterranean Limonium species (Galmés et al. 2017), which are close relatives of $M$. ferulaceum and inhabiting very similar environments.

From the three Rubisco haplotypes described in Limonium, the haplotype I, which is basal to the remaining two (Galmés et al. 2014), showed a biochemical limitation almost as high as the stomatal limitation under WD (Galmés et al. 2017). The derived haplotypes II and III had slower velocity (lower $\left.k_{\text {cat }}^{\mathrm{c}}\right)$, higher specificity for $\mathrm{CO}_{2}\left(S_{\mathrm{c} / \mathrm{o}}\right)$ and consequently lower $P_{\mathrm{N}}$ than that of haplotype I, which indicates that Rubisco evolution in the harsh habitats of Limonium favored Rubiscos with higher efficiency under low $C_{\mathrm{c}}$ (lower $g_{\text {tot }}$ ) (Galmés et al. 2014, 2017). As compared to Limonium haplotypes, M. ferulaceum Rubisco better resembled those of haplotypes II and III, with stomatal limitations being $c a$. 50\% of the total limitations (Fig. 3; Galmés et al. 2017). However, the kinetics of $M$. ferulaceum Rubisco did not match with the values reported for the Limonium haplotypes. It resembled the haplotypes II and III in having lower $K_{\mathrm{c}}, K_{\mathrm{o}}$, and $k_{\text {cat }}^{\mathrm{c}}$, but resembled haplotype I in having high $k_{\text {cat }}^{\mathrm{s}}$ and $k_{\text {cat }}^{\mathrm{c}} / K_{\mathrm{c}}$, and low $S_{\mathrm{c} / \mathrm{o}}$ and $k_{\text {cat }}^{0} / K_{\mathrm{o}}$. In fact, $M$. ferulaceum Rubisco had lower $S_{\mathrm{c} / \mathrm{o}}$ and $k_{\text {cat }}^{0} / K_{\mathrm{o}}$ and higher carboxylase catalytic efficiency $\left(k_{\text {cat }}^{\mathrm{c}} / K_{\mathrm{c}}\right)$ than any Limonium species (Table 4; Galmés et al. 2014).

Regarding this intermediate behavior between haplo- 


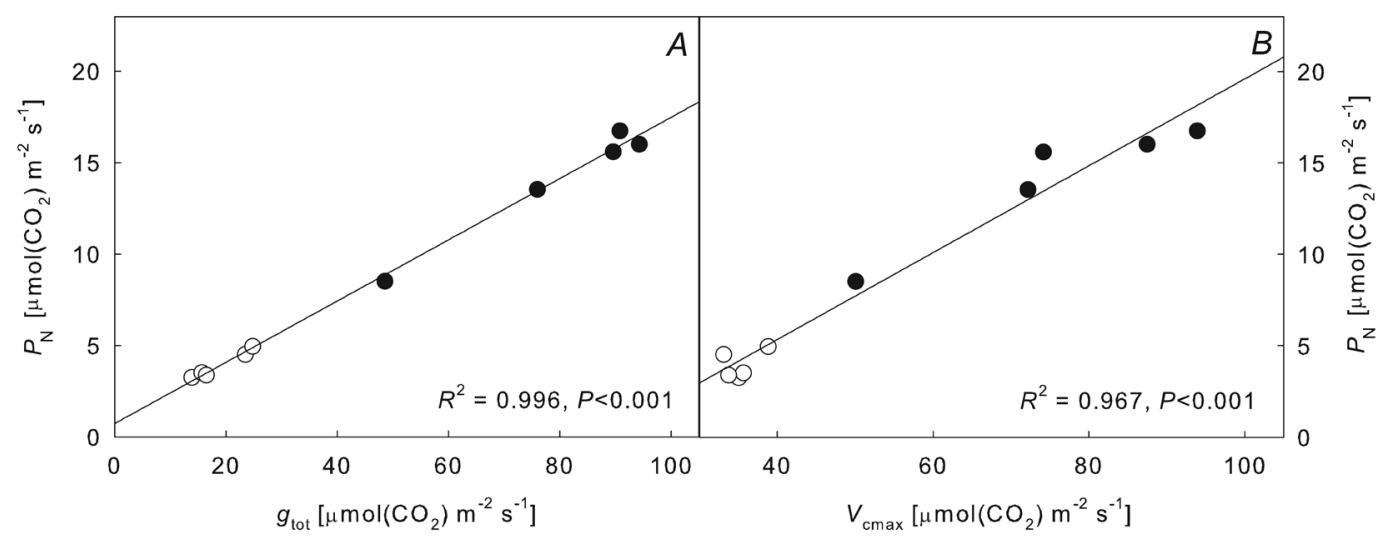

Fig. 4. The relationship between the net $\mathrm{CO}_{2}$ assimilation rate $\left(P_{\mathrm{N}}\right)$ and the total conductance to $\mathrm{CO}_{2}\left(g_{\text {tot }}\right)(A)$ and the maximum rate of Rubisco carboxylation $\left(V_{\mathrm{cmax}}\right)(B)$. Filled black circles represent well-watered (WW) plants and empty circles represent severe water deficit (WD) plants. The regression lines correspond to both treatments together. Considering treatments separately, $(A) \mathrm{WW}, R^{2}=0.978$; $\mathrm{WD}, R^{2}=0.968 ; P<0.001$ in both cases, and $(B) \mathrm{WW}, R^{2}=0.899, P<0.001 ; \mathrm{WD}, P>0.05$.

types I and II-III, there is larger number of differences between the $r b c \mathrm{~L}$ amino acid sequence of $M$. ferulaceum (Genbank number: KJ608035.1) and any of the Limonium Rubiscos (i.e. 14 residues), than between Limonium Rubiscos (i.e. 6 residues) (Table 1S). M. ferulaceum differs from Limonium haplotypes I, II, and III in 9, 11, and 12 positions, respectively. Consequently, M. ferulaceum $r b c \mathrm{~L}$ has higher similarity with haplotype I. In Limonium, changes in residues 309, 328, and 340 were related to higher specificity for $\mathrm{CO}_{2}$ and lower carboxylation velocity in haplotypes II-III (Galmés et al. 2014). In M. ferulaceum $\mathrm{rbcL}$, positions 309 and 328 are coincident with haplotype I and position 340 is coincident with haplotypes II-III (Table 1S). Nevertheless, further work is needed to ascertain an impact of these amino acid changes in the different kinetics observed among Rubiscos of M. ferulaceum and Limonium.

The $P_{\mathrm{N}}$ values of $M$. ferulaceum (Table 3 ) fall within the maximum stem $P_{\mathrm{N}}$ documented, ranging from 1.7 to 20.9 $\mu \operatorname{mol}\left(\mathrm{CO}_{2}\right) \mathrm{m}^{-2} \mathrm{~s}^{-1}$, which mostly correspond to species from arid environments having also leaf photosynthesis. In such species, leaves attain most of the year-round photosynthetic function, although stem photosynthesis can be similar or exceed that of the leaf in particular cases (reviewed in Ávila et al. 2014).

When comparing the leafless $M$. ferulaceum with leaved Limonium species grown under the same conditions, not only $P_{\mathrm{N}}$, but also $g_{\mathrm{s}}, g_{\mathrm{m}}, P_{\mathrm{g}} / C_{\mathrm{c}}, V_{\mathrm{cmax}}, J_{\max }$, and active Rubisco sites were lower in the former species than in most Limonium (Table 3; Galmés et al. 2017) denoting the limitations to photosynthesis and gas exchange of the stems. Under WW, $B_{\mathrm{T}}$ in $M$. ferulaceum was higher than 8 out of 13 Limonium species (Table 1; Conesa et al. 2019), indicating that the leafless plant habit is actually not detrimental when compared to leaved species. In this regard, $\mathrm{WUE}_{\mathrm{i}}$ in $M$. ferulaceum was among the highest values in Limonium (Table 3; Galmés et al. 2017), pointing to this as one of the main factors driving higher growth capacity of $M$. ferulaceum stems as compared to many Limonium leaves under nonstressing conditions. One of the most relevant benefits in arid species for switching to stem photosynthesis in the toughest season is the higher $\mathrm{WUE}_{\mathrm{i}}$ as compared to leaves, which has been related to the presence of sunken stomata, the vertical orientation of the stem diminishing photoinhibitory damage, and the lower sensitivity to environmental factors, such as drought, high temperature, low VPD, and low resources availability, among others (reviewed in Ávila et al. 2014, 2017; Santiago et al. 2016). The stem $\mathrm{CO}_{2}$ assimilation in these species has shown to be higher in the dry than in the wet season because of seasonal acclimation to higher light and temperature (Ávila-Lovera et al. 2017).

Contrary to the above, $M$. ferulaceum does not have sunken stomata (Fig. 3S), and photosynthesis and growth were dramatically affected under WD (Tables 1, 3). Hence, as compared to Limonium and paralleling WW, under WD, M. ferulaceum had much lower values of most of the measured photosynthetic parameters, much higher difference between treatments than those reported for Limonium species (Table 3; Galmés et al. 2014), and lower $\mathrm{B}_{\mathrm{T}}$ than any Limonium species (Conesa et al. 2019). Consequently, stem photosynthesis appears as a worse adaptive strategy to severe water deficit than that in the leaved Limonium species.

Altogether, results show that the thin and branched stems in $M$. ferulaceum cope well with the function of leaves in $\mathrm{C}_{3}$ species under WW conditions, but have important limitations to minimize growth reduction under harsh environments, as compared to leaves in Limonium. The severe water deficit resulted in high decreases in growth and water consumption but also adaptations related to increased water-use efficiency, such as increased $\mathrm{R} / \mathrm{S}$, and increased mesophyll airspaces leading to increased $g_{\mathrm{m}}$ and especially the $g_{\mathrm{m}} / g_{\mathrm{s}}$ ratio. There was a tight control of $P_{\mathrm{N}}$ by $V_{\text {cmax }}$ and $g_{\text {tot }}$, whereas the main limitation to $P_{\mathrm{N}}$ under WW was biochemical (i.e. Rubisco concentration and activity) and under WD diffusive (mostly stomatal).

Given the distribution of $M$. ferulaceum in the Mediterranean Basin, with narrow and disjunct populations (Lledó et al. 2003), increased intensity and duration of drought periods as predicted by the climate change scenario may have a negative impact for population survivorship, 
with dramatic effects on the species' distribution. Thus, despite the resilience to stress supposed to leafless species inhabiting harsh environments, M. ferulaceum showed less adaptability as compared to Limonium species, which may be considered to properly define managing strategies for conservation purposes.

\section{References}

Ambràmoff M.D., Magalhães P.J., Ram S.J.: Image processing with ImageJ. - Biophotonics Int. 11: 36-42, 2004.

Aschan G., Pfanz H.: Non-foliar photosynthesis - a strategy of additional carbon acquisition. - Flora 198: 81-97, 2003.

Ávila E., Herrera A., Tezara W.: Contribution of stem $\mathrm{CO}_{2}$ fixation to whole-plant carbon balance in nonsucculent species. Photosynthetica 52: 3-15, 2014.

Ávila-Lovera E., Zerpa A.J., Santiago L.S.: Stem photosyntheis and hydraulics are coordinated in desert plant species. - New Phytol. 216: 1119-1129, 2017.

Bernacchi C.J., Portis A.R., Nakano H. et al.: Temperature response of mesophyll conductance. Implications for the determination of Rubisco enzyme kinetics and for limitations to photosynthesis in vivo. - Plant Physiol. 130: 1992-1998, 2002.

Berveiller D., Kierzkowski D., Damesin C.: Interspecific variability of stem photosynthesis among tree species. - Tree Physiol. 27: 53-61, 2007.

Bréda N., Huc R., Granier A., Dreyer E.: Temperate forest trees and stands under severe drought: a review of ecophysiological responses, adaptation processes and long-term consequences.Ann. For. Sci. 63: 625-644, 2006.

Carriquí M., Cabrera H.M., Conesa M.À. et al.: Diffusional limitations explain the lower photosynthetic capacity of ferns as compared with angiosperms in a common garden study. Plant Cell Environ. 38: 448-460, 2015.

Chaves M.M., Flexas J., Pinheiro C.: Photosynthesis under drought and salt stress: regulation mechanisms from whole plant to cell. - Ann. Bot.-London 103: 551-560, 2009.

Chaves M.M., Maroco J.P., Pereira J.S.: Understanding plant responses to drought - from genes to the whole plant. - Funct. Plant Biol. 30: 239-264, 2003.

Chaves, M.M., Pereira J.S., Maroco J. et al.: How plants cope with water stress in the field. Photosynthesis and growth. Ann. Bot.-London 89: 907-916, 2002.

Comstock J.P., Ehleringer J.R.: Contrasting photosynthetic behavior in leaves and twigs of Hymenoclea salsola, a greentwigged warm desert shrub. - Am. J. Bot. 75: 1360-1370, 1988

Conesa M.À., Mus M., Galmés J.: Leaf size as a key determinant of contrasting growth patterns in closely related Limonium (Plumbaginaceae) species under well-watered and severe water deficit conditions. - J. Plant Physiol. 240: 152984, 2019.

Correia O., Ascensão L.: Summer semi-deciduous species of the Mediterranean landscape: A winning strategy of Cistus species to face the predicted changes of the Mediterranean climate. In: Ansari A.A., Gill S.S., Abbas Z.K., Naeem M. (ed.): Plant Biodiversity: Monitoring, Assessment and Conservation. Pp. 195-217. CABI International, Wallingford 2017.

Erben M.: Limonium. - In: Castroviejo S., Aedo C., Cirujano S. et al. (ed.): Flora Iberica. Vol. 3. Pp. 2-143. Real Jardín Botánico-C.S.I.C., Madrid 1993.

Farquhar G., von Caemmerer S., Berry J.A.: A biochemicalmodel of photosynthetic $\mathrm{CO}_{2}$ assimilation in leaves of $\mathrm{C}_{3}$ species. - Planta 149: 78-90, 1980.

Flexas J., Díaz-Espejo A., Berry J.A. et al.: Analysis of leakage in IRGA's leaf chambers of open gas photosynthesis para- meterization. - J. Exp. Bot. 58: 1533-1543, 2007.

Flexas J., Díaz-Espejo A., Conesa M.À. et al.: Mesophyll conductance to $\mathrm{CO}_{2}$ and Rubisco as targets for improving intrinsic water use efficiency in $\mathrm{C}_{3}$ plants. - Plant Cell Environ. 39: 965-982, 2016.

Flexas J., Díaz-Espejo A., Gago J. et al.: Photosynthetic limitations in Mediterranean plants: a review. - Environ. Exp. Bot. 103: 12-23, 2014.

Flexas J., Niinemets U., Gallé A. et al.: Diffusional conductances to $\mathrm{CO}_{2}$ as a target for increasing photosynthetic water-use efficiency. - Photosynth. Res. 117: 45-59, 2013.

Galmés J., Andralojc P.J., Kapralov M.V. et al.: Environmentally driven evolution of Rubisco and improved photosynthesis and growth within the $\mathrm{C}_{3}$ genus Limonium (Plumbaginaceae). New Phytol. 203: 989-999, 2014.

Galmés J., Flexas J., Keys A.J. et al.: Rubisco specificity factor tends to be larger in plant species from drier habitats and in species with persistent leaves. - Plant Cell Environ. 28: 571-579, 2005.

Galmés J., Flexas J., Savé R., Medrano H.: Water relations and stomatal characteristics of Mediterranean plants with different growth forms and leaf habits: responses to water stress and recovery. - Plant Soil 290: 139-155, 2007 a.

Galmés J., Medrano H., Flexas J.: Photosynthetic limitations in response to water stress and recovery in Mediterranean plants with different growth forms. - New Phytol. 175: 81-93, $2007 b$.

Galmés J., Molins A., Flexas J., Conesa M.À.: Coordination between leaf $\mathrm{CO}_{2}$ diffusion and Rubisco properties allow maximizing photosynthetic efficiency in Limonium species. Plant Cell Environ. 40: 2081-2094, 2017.

Galmés J., Perdomo J.A., Flexas J., Whitney S.M.: Photosynthetic characterization of Rubisco transplantomic lines reveals alterations on photochemistry and mesophyll conductance. Photosynth. Res. 115: 153-166, 2013.

Grassi G., Magnani F.: Stomatal, mesophyll conductance and biochemical limitations to photosynthesis as affected by drought and leaf ontogeny in ash and oak trees. - Plant Cell Environ. 28: 834-849, 2005.

Harley P.C., Loreto F., Di Marco G., Sharkey T.D.: Theoretical considerations when estimating the mesophyll conductance to $\mathrm{CO}_{2}$ flux by the analysis of the response of photosynthesis to $\mathrm{CO}_{2}$. - Plant Physiol. 98: 1429-1436, 1992.

Lawlor D.W., Cornic G.: Photosynthetic carbon assimilation and associated metabolism in relation to water deficits in higher plants. - Plant Cell Environ. 25: 275-294, 2002.

Lledó M.D., Erben M., Crespo M.B.: Myriolepis, a new genus segregated from Limonium (Plumbaginaceae). - Taxon 52: 67-73, 2003.

Lledó M.D., Erben M., Crespo M.B.: Myriolimon, a new name for a recently published Myriolepis (Plumbaginaceae). Taxon 54: 811-812, 2005.

Ludlow M.M.: Strategies of response to water stress. - In: Kreeb K.H., Richter H., Hinckley T.M. (ed.): Structural and Functional Responses to Environmental Stresses. Pp. 269-281. SPB Academic Publishing, The Hague 1989.

Martins S.C.V., Galmés J., Molins A., DaMatta F.M.: Improving the estimation of mesophyll conductance to $\mathrm{CO}_{2}$ : on the role of electron transport rate correction and respiration. - J. Exp. Bot. 64: 3285-3298, 2013.

McDowell N., Pockman W.T., Allen C.D. et al.: Mechanisms of plant survival and mortality during drought: why do some plants survive while others succumb to drought? - New Phytol. 178: 719-739, 2008.

Munns R.: Comparative physiology of salt and water stress. Plant Cell Environ. 25: 239-250, 2002. 
Nardini A., Lo Gullo M.A., Trifilò P., Salleo S.: The challenge of the Mediterranean climate to plant hydraulics: Responses and adaptations. - Environ. Exp. Bot. 103: 68-79, 2014.

Nilsen E.T.: Stem photosynthesis: extent, patterns, and role in plant carbon economy. - In: Gartner B.L. (ed.): Plant Stems. Pp. 223-240. Academic Press, San Diego 1995.

Nilsen E.T., Bao Y.: The influence of water stress on stem and leaf photosynthesis in Glycine max and Sparteum junceum (Leguminosae). - Amer. J. Bot. 77: 1007-1015, 1990.

Nilsen E.T., Sharifi M.: Carbon isotopic composition of legumes with photosynthetic stems from mediterranean and desert habitats. - Am. J. Bot. 84: 1707-1713, 1997.

Osmond C.B., Smith S.D., Gui-Ying B., Sharkey T.D.: Stem photosynthesis in a desert ephemeral, Eriogonum inflatum. Characterization of leaf and stem $\mathrm{CO}_{2}$ fixation and $\mathrm{H}_{2} \mathrm{O}$ vapor exchange under controlled conditions. - Oecologia 72 : 542-549, 1987.

Pfanz H., Aschan G., Langenfeld-Heyser R. et al.: Ecology and ecophysiology of tree stems: corticular and wood photosynthesis. - Naturwissenschaften 89: 147-162, 2002.

Santiago L.S., Bonal D., De Guzman M.E., Ávila-Lovera E.:
Drought survival strategies of tropical trees. - In: Goldstein G., Santiago L.S. (ed.): Tropical Tree Physiology. Pp. 243-258. Springer International Publishing, Basel 2016.

Scoffoni C., Chatelet D.S., Pasquet-Kok J. et al.: Hydraulic basis for the evolution of photosynthetic productivity. - Nat. Plants 2: 16072, 2016.

Tinoco-Ojanguren C.: Diurnal and seasonal patterns of gas exchange and carbon gain contribution of leaves and stems of Justicia californica in the Sonoran Desert. - J. Arid Environ. 72: 127-140, 2008.

Tomàs M., Flexas J., Copolovici L. et al.: Importance of leaf anatomy in determining mesophyll diffusion conductance to $\mathrm{CO}_{2}$ across species: quantitative limitations and scaling up by models. - J. Exp. Bot. 64: 2269-2281, 2013.

Vandegehuchte M.W., Bloemen J., Vergeynst L.L., Steppe K.: Woody tissue photosynthesis in trees: salve on the wounds of drought? - New Phytol. 208: 998-1002, 2015.

Yokota A., Canvin D.T.: Ribulose bisphosphate carboxylase/ oxygenase content determined with $\left[{ }^{14} \mathrm{C}\right]$ carboxypentitol bisphosphate in plants and algae. - Plant Physiol. 77: 735-739, 1985.

(C) The authors. This is an open access article distributed under the terms of the Creative Commons BY-NC-ND Licence. 